\title{
'It definitely made a difference': A grounded theory study of yoga for pregnancy and women's self-efficacy for labour
}

\author{
Virginia Campbell*, Mary Nolan \\ University of Worcester, St John's Campus, Henwick Grove, Worcester WR2 6AJ, United Kingdom
}

\section{A R T I C L E I N F O}

Article history:

Received 16 May 2018

Revised 7 October 2018

Accepted 16 October 2018

\section{Keywords:}

Yoga

Pregnancy

Self-efficacy

Antenatal education

Grounded theory

Coping

\begin{abstract}
A B S T R A C T
Objective: To explore women's experience of attending yoga for pregnancy classes in order to generate a theory about which aspects, if any, are effective in enhancing self-efficacy for labour and birth.

Design: A longitudinal grounded theory study.

Methods: Semi-structured interviews were undertaken with women before they started yoga for pregnancy classes, after they had attended at least six classes, and finally, postnatally. Interview transcripts were analysed using constructive grounded theory and a self-efficacy framework.

Setting: Three yoga for pregnancy teachers' classes in England.

Participants: Twenty two women attending yoga for pregnancy classes.

Findings: Analysis of interviews with women at three time points led to a propositional theory that yoga for pregnancy enhances women's self-efficacy for labour by building their confidence and competence through a combination of techniques. These include repeated practice of a variety of pain management strategies, use of affirming language and the telling of positive labour stories, underpinned by yoga practice to lower somatic response to stress.
\end{abstract}

(c) 2018 Elsevier Ltd. All rights reserved.

\section{Introduction}

In addition to lower healthcare costs, straightforward birth without interventions has physiological and psychological benefits for women and families (Kassebaum et al., 2014; O'Mahony et al., 2010; Smith et al., 2016). Most women would prefer to birth their babies without medical intervention (Care Quality Commission, 2015; Wharton et al., 2017) and the reduction of birth interventions has been identified as an urgent healthcare priority (Amis, 2016). As pharmacological pain relief in labour results in more instrumental deliveries (Anim-Somuah et al., 2011), enabling women to use self-management strategies to cope with the intensity of labour should result in more women birthing their babies physiologically.

Antenatal education has the potential to teach women pain coping strategies which help them in labour, but unanswered questions remain around which approaches are most effective (Gagnon and Sandall, 2007; McMillan et al., 2009). Yoga for pregnancy (YfP) is gaining attention as an intervention which may help both calm women and lower their perceived pain in labour (Jones et al., 2012)

\footnotetext{
* Corresponding author at: Yew Tree House, High St, East Meon, Hants GU32 1QA, United Kingdom.

E-mail addresses: vcampbell192@gmail.com (V. Campbell), m.nolan@worc.ac.uk (M. Nolan).
}

thereby enabling them to birth their babies without pharmacological pain relief.

Systematic reviews give cautious support for the benefits of YfP in positively impacting stress and anxiety during pregnancy and reducing labour duration (Curtis et al., 2012; Jiang et al., 2015; Riley and Drake, 2013). However, the heterogeneity of dose and content of YfP interventions makes meta-analysis problematic. Many YfP studies (Deshpande et al., 2013; Satyapriya et al., 2013; Sun et al., 2010) have been carried out in developing countries where both the culture of childbirth and the practice of yoga are very different from western countries, making transferability of findings questionable. Most western yoga programmes comprise asanas (postures), Pranayama (breathing), Dhyana (meditation) and relaxation, but some authors (Maharana et al., 2013; Rakhshani et al., 2015) argue that YfP is an integrated therapy which should also encompass lifestyle and nutritional guidance. This raises questions about how YfP achieves its putative effects and whether it is a holistic intervention, or whether individual elements can be isolated and utilised in other forms of antenatal education (Curtis et al., 2012; Field, 2016).

Despite the synergy between yoga practice and the breathing and physical movements which many women use to manage labour pain, the majority of recent YfP trials (Bershadsky et al., 2014; Davis et al., 2015; Mitchell et al., 2012; Muzik et al., 2012; Newnham et al., 2014) investigate its effect on the psychological 
health of women, rather than on pain management. This has resulted in a lack of data on the effect of YfP on women's ability to manage labour.

Self-efficacy beliefs affect women's ability to succeed in the tasks they set themselves, and may influence both labour pain perception and perinatal outcomes (Tilden et al., 2016). Self-efficacy is defined as a person's belief in their ability to succeed in specific tasks and can be divided into self-efficacy expectancy and outcome expectancy. Self-efficacy expectancy is the belief that one will be able to perform certain behaviours successfully, for example, relax during labour. Outcome expectancy is the belief that performing the behaviour will result in the required outcome, i.e. that relaxing during labour will result in less pain (Lowe, 1991). Women with higher self-efficacy expectations are more likely to initiate and persist with pain management strategies (Bandura, 1977). Bandura (1977) hypothesised that self-efficacy beliefs were enhanced through four mechanisms. Lowe (1991) later related these to birth:

- Performance accomplishments (Successful previous experience with childbirth or other pain)

- Vicarious experience (Observing successful coping by others)

- Verbal persuasion (Being encouraged by influential others)

- Physiological states (Learning to recognise and reduce reactions such as panic).

Although it has been shown that self-efficacy is a modifiable construct and that higher self-efficacy is associated with diminished fear of birth, decreased labour pain, increased birth satisfaction and better perinatal outcomes (Tilden et al., 2016), little effort has been made to integrate it as a psychological theory into the design or evaluation of antenatal education programmes (Escott et al., 2009; Ip et al., 2009).

This paper arises from a study which explored women's experiences of YfP before analysing them through a self-efficacy lens. The aim was to generate a theory, grounded in women's voices, about which aspects of YfP are effective in enhancing women's ability to manage labour. Previous papers, (Campbell, 2018; Campbell and Nolan, 2016) have reported on aspects of YfP teachers' language and actions in classes which appear to impact on women's selfefficacy behaviour.

\section{Methods}

\section{Study design}

This longitudinal, grounded theory study employed semistructured interviews with women attending YfP classes. Interviews were conducted at three time points. The first interviews were undertaken before the women started YfP, the second near their babies' due date, and the third postnatally. To ensure the women had enough experience of YfP for it to have the potential to effect change, a minimum attendance at six classes was required for continued inclusion in the study at the second interview point. Grounded theory was used to generate a theory which would be relevant in implementing changes to antenatal educators' training and practice (Birks and Mills, 2011; Hall et al., 2012). A constructivist approach placed the women at the heart of the research, acknowledged multiple versions of 'the truth', and that the researcher and participants had a mutual influence on each other (Charmaz, 2003; Lincoln and Denzin, 2003).

\section{Setting}

In order to ensure a degree of homogeneity in the women's YfP experience, the research was restricted to classes run by YfP teachers trained by NCT (formerly known as the National Childbirth Trust). NCT YfP classes are run by teachers working on a selfemployed basis but within NCT operational and curriculum guidelines. NCT is the largest provider of antenatal teacher training and private antenatal education for parents in the UK. Annually, over 100,000 parents attend NCT courses for couples and an additional 2,000 women attend NCT YfP classes which are for women only. Women can attend YfP from the twelfth week of pregnancy until they have their baby. NCT YfP classes are unique in being run by teachers who not only have an accredited NCT yoga qualification, but also have a university degree in facilitating antenatal classes. The aims of NCT YfP classes explicitly include enhancing women's self-efficacy for labour in order to increase the number of positive births (NCT and The University of Worcester, 2016). In addition to the traditional aspects of yoga (breathing, positions, relaxation), NCT YfP classes aim to facilitate group bonding and increase knowledge of birth processes, aspects which are not necessarily part of non-NCT YfP classes.

\section{Recruitment}

Participants for the study were recruited via three NCT YfP teachers who were themselves participants in the first part of the study (Campbell and Nolan, 2016). The teachers emailed a study information sheet to women who booked to join their YfP classes between August 2014 and January 2015. Women willing to take part returned the consent form directly to the researcher. After this initial contact, all further communication about the study was between the researcher (VC) and the pregnant women.

\section{Participants}

Twenty-two women gave an interview before their first YfP class. The women were between 15 and 34 weeks pregnant (median 23 weeks) and ranged in age from 29 to 48 years (median 33 years). Fourteen of the women were expecting their first baby and eight were pregnant with their second or third child. The range of planned places of birth included three hospitals, two alongside birth centres and home. Two women had not decided where to have their baby at this stage.

At the second interview, when the women were between 35 and 41 weeks pregnant (median 37 weeks), seven women were excluded from the study on the basis of having had too little exposure to YfP. Two of these women did not attend any classes due to difficulties with the pregnancy or the advice of their GP. Five only attended one or two classes due to travelling distance or preference for a more vigorous class. Three women did not respond to requests for a second interview. One woman missed her second interview as she had her baby earlier than expected. In total, eleven of the women who participated in a first interview gave second interviews. Third interviews were held when the women's babies were between 9 days and 10 weeks old (median 5 weeks), determined by when it was possible to arrange a time to talk with the new mothers. All eleven women who had a second interview, and the woman who had her baby early, participated in a third interview.

Pseudonyms are used in the paper to protect the women's anonymity.

\section{Data collection}

In total, 45 interviews were conducted by telephone between August 2014 and August 2015. The interviewer aimed to adopt an informal tone and to be supportive in order to capture the 
women's perceptions and feelings in as relaxed a manner as possible (Taylor, 2005). Telephone-based active listening techniques were used to overcome the lack of more nuanced communication which can take place face-to-face (Creswell, 2012; King and Horrocks, 2010). Women were repeatedly reassured that there were no 'right' answers. Theoretical sensitivity led to questions which explored emerging themes being added to the interview topics as interviews progressed.

First interview topics included why the women were choosing to attend YfP, their approach to labour and feelings about the birth. Second interview topics included the women's thoughts about the YfP classes, how they were feeling about labour, how they thought they might manage contractions and their confidence in doing so. Third interview topics included the women telling their birth story, how they managed contractions, and what, if anything, made a difference to their ability to manage their labour.

Interviews lasted between 17 and 35 minutes (median 20). Consent for continued participation and permission to audio record interviews was renewed via email/phone with each woman before every interview. Interviews were professionally transcribed.

\section{Data analysis}

The interviews at each of the three time points were treated as separate datasets to allow for thematic variability to be identified. Data generation and analysis proceeded concurrently.

Each transcript was anonymised and read through several times to enable content familiarisation. Approximately 500 pages of text were coded line-by-line using NVivo software. Codes and emerging themes were written in the women's words wherever possible. This ensured that they were transparently grounded in the data, with an avoidance of over-abstraction (Bryant, 2002; Mills et al., 2006; Thomas and James, 2006). Field notes and memos were used to provide an audit trail, aid focus and theoretical sensitivity (Hall et al., 2012; Holton, 2007). Emerging concepts were continually tested using constant comparison techniques (Glaser and Strauss, 1967). Data sufficiency was achieved with no new themes emerging by the final interviews. Trustworthiness and rigour were enhanced by co-author discussion of themes and by a combination of manual and software analysis (Welsh, 2002).

The themes which emerged from the women's third interviews where they spoke about what had helped them in labour were explored through a self-efficacy framework (Bandura, 1977). This aided the emergence of a grounded theory which could be applied to YfP teacher training and practice.

\section{Reflexivity}

One of the researchers (VC) was an NCT YfP tutor and one $(\mathrm{MN})$ has no yoga training. The concept of researchers being either an insider or outsider has been challenged as restrictive and too simplistic (Mercer, 2007; Shope, 2006). VC undertook the data collection and was an insider with the women by virtue of being a mother and YfP teacher. She was also an outsider as she was not 'their' teacher, placing her in the fluid and multi-layered position Dwyer and Buckle (2009) represent as the hyphen between insider-outsider. In order to minimise potential bias, reflexive memos drawing on the researcher's beliefs and sense of 'place' within the study were created before and during observations, interviews and analytic work. Potential biases were discussed with MN who also reviewed the interview scripts to ensure they reflected emerging themes.

\section{Looking after myself and my baby}

Hoping for a natural or easier labour

Preparing for something I can't prepare for

Being calm and in control

Making friends

Fig. 1. First interview themes.

\section{Findings}

First interviews

Looking after myself and the baby

The pregnant women had broad aims for attending YfP, seeing it as a holistic therapy which could help with various physical and emotional aspects of the antenatal, intrapartum and postnatal period.

The breathing, positions... Friends and fitness, and pick up some tips on the way for the big day. (Wendy)

Many of the women's anxiety levels had increased during pregnancy. Others recognised that their habitual worrying or stress was not good for them and could impact upon their baby's health. The women said they hoped the classes would help reduce anxiety.

To switch off and relax... The more you are stressed, the more you put your body under stress, and the more the baby will pick up on it. (Elizabeth)

A few women mentioned anxiety resulting from the loss of previous babies.

It's taken all the naivety away... makes you worry about every little aspect. So I'm trying... to be more in a positive frame of mind. (Rebecca)

For some women, YfP was a way of avoiding excess weight gain. Many of them had reached a high level of physical fitness prepregnancy and wanted to engage in activity which they felt was safe and would help them retain strength and flexibility.

I've just started to feel that I'm putting on too much weight, so I wanted to make sure that I am staying fit; there are not many exercises that you can do during pregnancy. (Chloe)

Four subthemes emerged from the first interviews (Fig. 1):

- Hoping for a natural or easier labour

- Preparing for something I can't prepare for

- Being calm and in control

- Making friends.

\section{Hoping for a natural or easier labour}

Only one aim was common to all twenty-two women: to learn techniques such as breathing and relaxation to help them during the birth. 
To try and have some techniques or positions that... might calm me... To take your mind off the pain... keep your mind focused on that, rather than on the fact that it really hurts. (Lisa)

Many women articulated a strong desire to avoid medical intervention.

I'm aiming to have as natural a birth as possible. It's always been my goal. (Josie)

Most of the mothers expecting their second child were unhappy with how they had managed their previous labour. They hoped that attending YfP would give them practice in breathing and pain management strategies which would enable them to cope better.

I did NCT classes before, and they do teach you the breathing thing, but you kind of do it for 10 minutes as part of the class, whereas I think this will be better doing it once a week... In [my last] labour I held my breath, I was absolutely rubbish. I don't know why I couldn't apply everything I'd been shown, or what I was told to do, but I think doing something weekly it will mean hopefully, it will stick. (Rebecca)

\section{Preparing for something I can't prepare for}

Despite a desire to manage labour using their own resources, the women spoke of not feeling confident that they would be able to do so. They said they would accept or ask for pharmacological help if necessary as they did not know whether self-management strategies would work.

I want to have a natural birth. I know everybody says it and it never works, so if I have to have anything I will. But I want it to be as natural as possible... I'm realistic at the end of the day. All the people I have known lately it hasn't gone the way they wanted. (Chloe)

The first-time mothers spoke of not feeling confident in managing the unknown experience of labour pain.

I don't know exactly what's going to happen or how I will react. (Tessa)

The women's sense of lack of control had been fuelled by stories they had heard. They said that few women got the birth they wanted, so it was sensible to protect themselves by not raising their hopes too high. In some cases, the stories they had heard had convinced them that birth could not be other than awful.

Everyone tells you horror stories. (Wendy)

I know it's going to be absolutely horrendous. (Elizabeth)

Even the second-time mothers lacked confidence that they could have the birth they hoped for, either because they had not had a good experience first time around, or because they did not trust a second birth to go as well as the first.

I'm actually probably a little more nervous this time round... because I kind of know now what it's all about... I had such a good birth that I am worried that... I am kind of out of my luck. (Inge)

\section{Being calm and in control}

A complex subtheme emerged expressing how the women were grappling with a cognitive dissonance around control in labour. They wanted an easy, and for most, as natural a labour as possible and were trying to plan for that by attending yoga. But at the same time, they said that it was impossible to prepare for a natural labour and also that it was unlikely to happen. Whilst accepting a lack of control over some events of their labour and that the safety of their baby must always be the priority, they wanted to be in control of their mental and emotional state, however the birth progressed.
My hope for the birth is... that we end up with a healthy baby... I understand that my wishes would always be secondary... But in an ideal world, my hope... is that I'll stay in control, that there won't be any intervention, that I won't need to have any drugs... and it's all as natural and calm as possible. (Tessa)

In addition to saying how yoga might help them stay in control by enabling them to cope with contractions, the women described how practising techniques to 'turn inwards' might help them to not panic, no matter what course their labour took.

Being able to sort of channel the breathing... I can try and relax and take myself to a more positive place. Because I think even if all is going crazy ... if you're in a calm place it's much easier to deal with those things. (Josie)

\section{Making friends}

Although not directly related to labour self-efficacy at this stage, the fourth subtheme to emerge when the women were asked why they were choosing to attend YfP was a desire to make friends.

Since I've become pregnant... there's a need to sort of surround yourself with people... going through exactly the same. Those things that you sit and worry about, they are worrying about as well. (Ailsa)

Second interviews with the pregnant women - after attending YfP classes

Gaining confidence in managing labour

The second interviews offered the opportunity to explore both whether the women felt their ability to manage labour had changed and also how they perceived any change might have been effected. An overall theme of gaining confidence emerged with the women saying that YfP had helped them feel more positive about their ability to have the labour they hoped for. Their hopes for a birth without medical intervention appeared to have strengthened: at this point, all the women stated a preference for a physiological labour, even those who had not mentioned it in their initial interview.

I've got loads of people around me that keep telling me... it's not going to work... But I know that it is a natural process and if you do keep calm it will make it a lot easier... I've kind of educated myself and my body to think that I can do it. (Chloe)

Four subthemes emerged from the second interviews. These were related to the subthemes which emerged from the earlier interviews but had a different strength or focus (Fig. 2):

- Practising techniques for labour

- Learning from each other

- Being in control

- Preparing for something I can't prepare for.

\section{Practising techniques for labour}

All the women said that learning different breathing techniques in combination with repeated practice of labour positions and relaxation had led them to feel more confident and prepared for birth.

The yoga has definitely given me way more practical things I'll actually use when it comes to the labour and birth, like the breathing and positions... We've done it every single week... it's given it much more of a kind of embedded feel. (Faye)

The women described a variety of coping strategies they had practised, differentiating them and showing an awareness of which ones might work for them. 


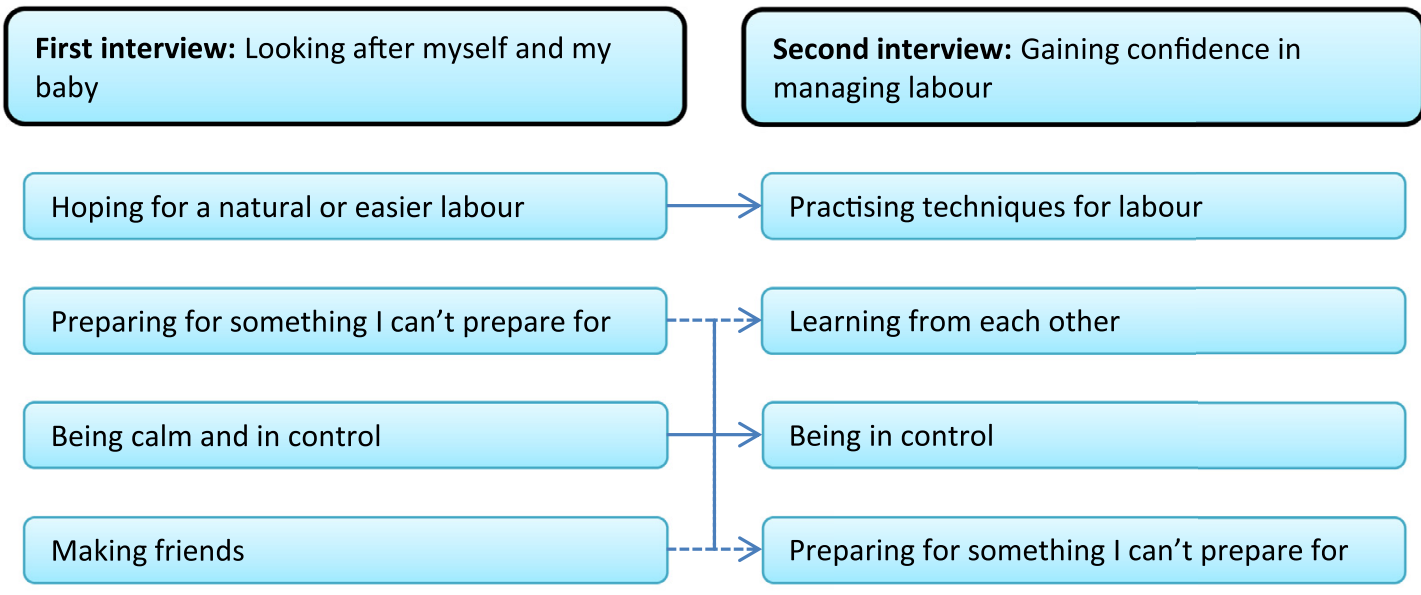

Fig. 2. First and second interview themes.

I've got a little arsenal of tricks and things that I can try and pull together... So I feel confident I've got enough that I can sort of try and keep me occupied. (Wendy)

There are certain techniques that I prefer to others... The counting one... I feel personally for me will work better than others. (Tessa)

Learning from each other

The women's confidence had increased after 'show and tell' visits by previous class members who had returned with their babies. Hearing mothers who had recently given birth describe how yoga techniques had helped them in labour was influential in enabling the pregnant women to believe the techniques could work for them too.

All of them [are] very, very positive about the benefits of what the yoga brought to them... It puts faith in the fact that what you're doing in the sessions... are going to be beneficial. (Tessa)

The women enjoyed the positive class ethos where both the teacher and second-time mothers spoke of straightforward birth as achievable. These stories helped counteract negative input from other sources.

We had one lady come back... with her baby, and she'd had like a really straightforward birth... That really helped me to hear a positive story as opposed to people's horror stories. (Kirsten)

\section{Being in control}

At this stage, 'Being in control' continued to develop as a subtheme. Firstly, the women said yoga was helping them to approach labour in 'the right frame of mind' (Cassie).

Yoga maybe puts you more in tune with your body... I feel quite empowered in a way that birth isn't something that is going to happen to me: I can kind of be active in it. (Terri)

Secondly, they were making decisions about their birth environment which had the potential to make it more straightforward.

One of the girls that brought their babies in, they'd had a water birth and said how much it helped... I'm hoping for a water birth as well now. (Chloe)

\section{Preparing for something I can't prepare for}

Although the women felt more confident, none felt fully confident or in control. There was less mention about fearing labour pain, but the first time mothers particularly still spoke of not knowing what to expect. All the mothers recognised the possibility of unforeseen medical complications. The women described their fear of losing control once they arrived in hospital or if medical intervention was necessary.

I feel more confident. Whether I feel $100 \%$ prepared? Probably not because I have no idea what I really will go through. (Adali)

The time spent at yoga classes had helped the women to reconcile the opposing paradigms of both retaining control and giving it to medical professionals. They described how they might be able to retain control mentally even if their hopes for a natural labour did not happen.

One half of me is consciously aware that [labour] might not go exactly to plan; but the other part of me is sort of aware that if I can think about my breathing and... how I want to approach it from a kind of a mental perspective... that will help with the whole process. Yoga has helped me focus all those ideas. (Terri)

\section{Postnatal interviews}

Having a positive labour experience

Postnatally, the women spoke about how they had used the skills they had learned in YfP. Their descriptions of remaining calm, confident and in control during their labours were consistent and powerful, as were their stories of managing their labours without medical intervention. The women attributed their positive labour experiences to what they had learned in YfP.

I'm really pleased that the actual birth happened the way I wanted it... I generally think of the whole experience with a real sense of calmness... and I definitely think that's from yoga. (Terri)

All twelve women realised their hope of giving birth vaginally. Eleven of the twelve women used only natural pain relief methods or combined these with Entonox. One woman accepted a syntocinon drip to speed up her labour. Another had an epidural once she was in second stage of labour and her baby's birth was assisted with forceps.

The three subthemes which emerged postnatally were closely related to those which had emerged at the second interview stage (Fig. 3):

- Using techniques to manage labour

- Being calm, confident and in control

- Being positive and telling stories. 
First interview: Looking after myself and my baby
Second interview: Gaining confidence in managing labour
Postnatal interview: Having a positive labour experience

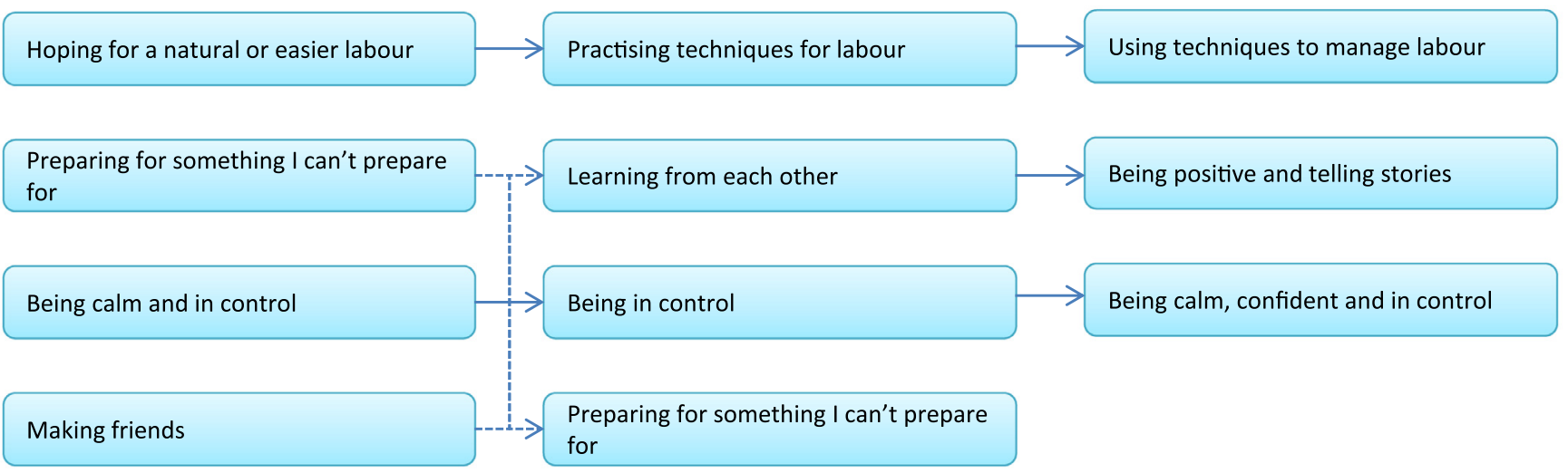

Fig. 3. Progression of themes through all interviews.

Using techniques to manage labour

All the women spoke compellingly of the benefits they gained from using breathing techniques, labour positions and movements they had practised in YfP.

It was really just the breathing; that was really what got me through the entire labour. (Chloe)

I used some of the positions we were taught - different labouring positions like being on all fours and rocking backwards and forwards. (Cassie)

The women emphasised how repeated practice of pain management strategies in YfP classes had made the techniques feel comfortable and familiar. They said that because they had been taught a variety of coping strategies, they were able to find the right ones for them.

It was the teaching it every week... The calm... repeating... definitely increased my confidence. (Kirsten)

What was really helpful was... she always encouraged us to try different kinds of positions... to see which position is the most comfortable for me... It was easier to try different things [in labour] because I had tried them already during the course. (Adali)

Being calm, confident and in control

Many of the women spoke about how they remained calm during the birth of their babies.

I did stay so calm during the labour... I literally spent the whole time with my eyes closed just in my own dream world... I didn't scream, didn't swear, just got on and did it. (Chloe)

I was ridiculously calm during the labour. (Tessa)

I was completely at peace and I think being relaxed then allowed it to all progress really nicely. (Paula)

The women said this sense of calm was due to effective use of the pain management strategies they had practised in YfP sessions.

The midwife kept saying to me, "Oh you're being so instinctive, everything you are doing is so instinctive" and I didn't correct her, but I just thought: if I hadn't been taught any of this, I wouldn't have been able to do it... It kept me calmer for longer, definitely. (Kirsten)
The confidence resulting from practice in pregnancy had enhanced the women's feelings of trust in their body.

I had been practising yoga and so therefore had built a relationship up with my body... Having confidence in your body, because that's the most important thing: knowing that you can do it, believing that you can. (Paula)

I was just completely in trust of my body... It was just as though my body knew exactly what to do. (Inge)

The women's birth stories showed that they had felt empowered to make decisions and act in ways which felt right for them during labour.

The midwife and other people were telling me to get into certain positions and I did try... but... it was... more painful... So I chose the positions....Even down to the end she told me I had to lay down to give birth; and I wanted to be in the position that I was comfortable with, and I think that was listening to my body. (Chloe)

Although using breathing techniques and labour positions had helped them manage contractions, two of the women were not calm throughout their labours. One had a very fast labour and gave birth in the triage room. Ironically, another was disappointed that she appeared so calm that she was unable to convince her caregivers that her labour had stalled despite her instincts telling her that she would need medical assistance. She asked for an epidural a number of times before becoming distressed.

I wish I'd been a bit more forceful, because they said that I didn't need [an epidural, that]... I'd be fine and it would all be over soon... By the end I definitely wasn't in control, I was begging for help and absolutely shattered, and just desperate for somebody to do something. (Kirsten)

\section{Being positive and telling stories}

The second strongest theme to emerge postnatally captured the benefits of hearing positive stories in the YfP classes, which the women had also referred to in their second interviews.

Hearing birth stories from other mums that came back to yoga class just sort of put you in the right frame of mind, and sort of focused me on the things I did want and the things I didn't. (Cassie) 
Table 1

Mapping YfP content against Bandura's (1977) categories and Lowe's (1991) processes.

\begin{tabular}{|c|c|c|}
\hline Bandura (1977) & Lowe (1991) & Yoga for pregnancy classes \\
\hline Performance accomplishments & $\begin{array}{l}\text { Successful coping experiences such } \\
\text { as past childbirth or previous } \\
\text { experience with pain }\end{array}$ & $\begin{array}{l}\text { Secondary performance accomplishments: practising } \\
\text { breathing, labour positions, visualisations and other } \\
\text { coping strategies }\end{array}$ \\
\hline Vicarious experience & $\begin{array}{l}\text { Observing successful coping by } \\
\text { others }\end{array}$ & $\begin{array}{l}\text { Stories told by the teacher, other class participants and } \\
\text { women returning to 'show and tell' }\end{array}$ \\
\hline Verbal persuasion & $\begin{array}{l}\text { Being encouraged by influential } \\
\text { others }\end{array}$ & $\begin{array}{l}\text { Positive statements and affirmations spoken throughout } \\
\text { the classes by the teachers and pregnant women }\end{array}$ \\
\hline $\begin{array}{l}\text { Physiological states (somatic } \\
\text { awareness and response) }\end{array}$ & $\begin{array}{l}\text { Learning to recognise and reduce } \\
\text { reactions, such as panic, in } \\
\text { response to the anticipation or } \\
\text { experience of a stressful event. }\end{array}$ & $\begin{array}{l}\text { Relaxation, meditation and practical work including } \\
\text { modelling breathing through contractions whilst noticing } \\
\text { and mitigating tension responses }\end{array}$ \\
\hline
\end{tabular}

The women remembered specific positive affirmations the teachers had used in YfP classes that had helped them in labour. They appreciated how the teachers had encouraged them to believe in their ability to have control over their birth experience.

[The affirmation] kept going through my mind... "We've done that push; that's over and done with and we don't have to do that push again; it's one step closer to meeting your baby"... That's just what I was thinking 'Yes, done that, just waiting for the next one'; and I was actually willing the next one along - I wasn't dreading the next one actually, I was willing it along because he would be here sooner. (Chloe)

A dissonant voice was heard from a woman who had expressed more anxiety than the others at the second interview stage. Despite giving birth without medical intervention as she had hoped, she remained anxious throughout her labour.

Sadly, the whole labour... I felt really quite anxious and frightened... even though I gave birth naturally... I kept thinking all the worst case kind of... Unfortunately, it was quite detrimental I think to the actual labour... it was all I could focus on. (Grace)

\section{Discussion}

The women's hopes for straightforward birth, coupled with uncertainty around their ability to achieve it, resonate with existing literature, as does their sense of confidence and control after attending YfP (Doran and Hornibrook, 2013; Eri et al., 2015; Mitchell, 2013). All the women said YfP enhanced their ability to manage their labour.

\section{Definitely, it definitely made a difference. (Kirsten)}

Analysing the findings within a self-efficacy framework shows how the YfP elements which the women said helped them most (skills practice, positive stories, affirmations and learning to relax) map closely to Bandura's (1977) and Lowe's (1991) work on efficacy-enhancing processes (Table 1, Fig. 4).

\section{Performance accomplishments}

Performance accomplishment, for example perceived 'success' in managing a previous labour, is the most influential source of efficacy beliefs (Bandura, 1977; Cunqueiro et al., 2009). In addition to the confidence gained from personal achievement, performance mastery reduces somatic response by mediating anxiety. For women who have not had a baby, or not had what they perceive as a successful experience of labour, practising through modelling behaviour (secondary performance accomplishment) has been hypothesised as the most effective way to enhance self-efficacy perception (Bandura, 1986). This resonates with the findings from the present study where all the women said the main factors enabling them to manage their labour were learning pain coping skills and the confidence they gained from repeatedly practising them.

The literature has found an uncertain relationship between antenatal skills education, use of self-management strategies in labour and the effectiveness of such strategies in terms of reduced use of pharmacological pain relief (Bergström et al., 2009; Escott et al., 2005). In comparison, all the women in the present study spoke of how the breathing and positions they had learned in YfP helped in labour. Belief in one's own ability to control labour pain predicts both the intention to use and the actual use of coping strategies (Escott et al., 2009; Ip et al., 2009; Lowe, 1989). Yet women's outcome expectancies have consistently been shown to be greater than self-efficacy expectancies: women believe more in the efficacy of coping strategies than in their ability to use them successfully (Beebe et al., 2007; Cunqueiro et al., 2009; Ip et al., 2005; Lowe, 1993; Salomonsson et al., 2013b). It has been suggested that this might be due to insufficient practice of pain management strategies in the antenatal period (Escott et al., 2009; Larsen and Plog, 2012; Schwartz et al., 2015). The women in this study attended more sessions than participants in other studies of antenatal education interventions aimed at increasing self-efficacy (Bergström et al., 2009; Escott et al., 2005; Larsen and Plog, 2012; Maimburg et al., 2010), and attributed their confidence to repeated practice of coping techniques. It is possible that their increased confidence in their ability to use strategies effectively was due to regular practice which, in turn, resulted in their trying more coping strategies and persisting with them for longer, thus leading to increased success in pain management.

It may also be surmised that the variety of coping strategies taught in YfP (Campbell, 2018) helped the women to become more aware of their personal coping style, resulting in their using the strategies which suited them best. This resonates with studies indicating that women might benefit from antenatal education which helps them to choose from and incorporate a wide range of coping strategies covering all the different coping styles (Carlsson et al., 2014; Escott et al., 2004; Escott et al., 2009; Karlsdottir et al., 2014; Levett et al., 2016; Salomonsson et al., 2013a;).

\section{Vicarious experience}

The significance of hearing positive birth stories was a recurring theme in the women's interviews, supporting Bandura's (1977) hypothesis that vicarious experience is an influential factor in selfefficacy beliefs. Before the women began YfP, 'horror stories' and previous experience had convinced them that joyous, straightforward birth was not usually possible. The positive stories they heard in YfP not only increased their confidence but also affected decisions they made before and during labour. This is in line with findings from several studies (Brand et al., 2014; Doran and Hornibrook, 2013; Savage, 2006). The effect of story-telling on selfefficacy is complex, as effect is linked with the content and per- 
Postnatal interview: Having a positive labour experience

\section{Self-efficacy enhancing processes}
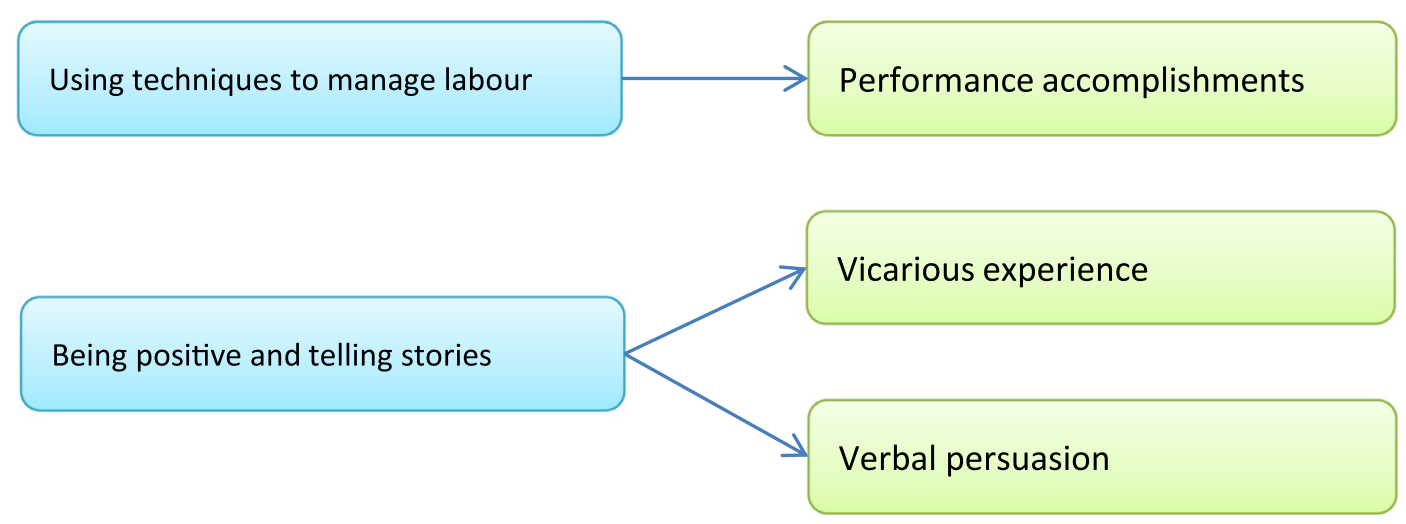

Being calm, confident and in control

\section{Somatic awareness}

Fig. 4. How the postnatal interview themes relate to efficacy-enhancing techniques.

spective of the story as well as the credibility of the story-teller (Carlsson et al., 2015; Fenwick et al., 2005; Kay et al., 2017; Taheri et al., 2014; Thomson et al., 2017). Stories showing the courage and power of women, and infused with a belief in normal birth, inspire confidence, whilst negative stories promote catastrophising and reduce use of pain coping strategies (Bar-On et al., 2014; Fisher et al., 2006; Jackson et al., 2005; Taheri et al., 2014).

\section{Verbal persuasion}

Self-efficacy can be strengthened through encouragement, particularly by people regarded as influential or peer group role models (Bandura, 1977; Cunqueiro et al., 2009; Salomonsson et al., 2013a). Verbal persuasion in the YfP classes took many forms, for example linking coping strategies and breathing practice to positive words such as 'calm' and 'easy', and repeated positive statements about women's ability to birth. The women valued the positive ethos in the YfP classes and four of them used affirmations they had practised in YfP to help them in labour. Verbal persuasion is most likely to succeed when, as in YfP, it is used in conjunction with other methods of increasing self-efficacy (Bandura, 1977): it is easier to convince a mother that she can succeed if she is confident in her coping skills and has seen her peer group succeed before her. The benefits of mastering a range of self-coping techniques are only realised in women who have a conviction that coping is possible.

\section{Physiological states: somatic awareness and response}

The women in this study expressed a desire from their first interviews for YfP to help them get into the 'right frame of mind' for labour. Later, they attributed a sense of calm and confidence to having attended YfP. A woman's state of mind affects her labour pain experience, birth choices and outcomes (Alder et al., 2007; Koelewijn et al., 2017; Whitburn et al., 2014). Anxiety is associated with low efficacy expectancy and reduced use of coping strategies (Beebe et al., 2007; Lowe, 2000; Salomonsson et al., 2013b;
Schwartz et al., 2015; Sieber et al., 2006). Despite the abundant evidence that anxiety has multiple negative effects on pregnancy and birth, there is a relative paucity of evidence on antenatal interventions to reduce it (Marc et al., 2011).

Yoga, with its focus on breathing, meditation and relaxation is ideally placed to help women achieve the somatic awareness which Bandura (1977) hypothesised was the fourth source of selfefficacy. The reduction in anxiety which the women in this study expressed is mirrored by findings in YfP literature (Newnham et al., 2014; Riley and Drake, 2013; Sheffield and Woods-Giscombé, 2015). Interventions aimed at increasing self-efficacy work best when techniques for reducing somatic arousal are combined with mastery techniques, vicarious experience and verbal persuasion (Bandura, 1982). Women who believe themselves able to cope with labour have a reduced stress response (Carlsson et al., 2015) and the use of pain coping strategies itself reduces stress responses and increases feelings of control (Slade et al., 1993; Spiby et al., 2003). The women in this study benefited in labour from the effects of this combination of efficacy-enhancing strategies.

\section{Strengths and limitations}

This is the first study where the development of women's thoughts around their hopes for birth, ability to manage labour and which aspects of YfP they find most effective, have been explored over time, and analysed in relation to self-efficacy theory.

A strength of the study is the richness of the data which was generated from interviews with women at different stages of their transition to parenthood. Limitations are that the participants were restricted to women who attended multiple sessions of self-funded YfP classes. The YfP teachers did not record whether they sent invitations to participate in the study to every woman who enquired about their classes, and it is unknown how many women did not respond to the invitation. The findings may therefore not apply to women who were not invited to take part in the study, who chose not to participate, or who withdrew after the first interview. 
A strength of the study is the consistency of the intervention as the YfP classes shared a common ethos, structure and curriculum. A corresponding limitation is that the results are not necessarily transferable to YfP classes which are facilitated by non-NCT YfP teachers.

\section{Conclusion}

The aim of this study, to generate a theory about which aspects of YfP are effective in enhancing women's ability to manage labour, was achieved. The evidence from this study is that YfP enhances women's self-efficacy for labour through a combination of efficacyenhancing strategies. Increased confidence and competence enable women to remain calmer, to mobilise pain management skills and take greater control of their labour. The congruence between what the women said helped them and self-efficacy theory suggests that the elements in YfP classes which are most effective for enhancing women's ability to manage labour are:

- The inclusion of all four efficacy-enhancing strategies

- Multiple opportunities for practice

- Being taught a variety of pain management strategies covering different coping styles.

The results from this study suggest that in order to increase positive, straightforward birth, antenatal education programmes need to incorporate multi-focused interventions which recognise the complex interplay between these efficacy enhancing methods.

\section{Conflict of interest}

The authors declare they have no conflict of interest.

\section{Ethical approval and consent to participate}

Ethics approval for the study was gained from the University of Worcester Institute of Health and Society Ethics Committee and NCT. The study adhered to the principles outlined in the Charter for Ethical Research in Maternity Care. The women were provided with a study information leaflet and written informed consent to participate was obtained. The women consented that their experiences could be used in publications provided no details that could identify them were included.

\section{Funding sources}

The study was part of a PhD studentship supported by an HEI. Some expenses were paid by the NCT.

\section{Availability of data and materials}

Interview transcripts will not be made publicly available in line with participant consent.

\section{Acknowledgements}

We are grateful to both the women and teachers who participated in this study.

\section{References}

Alder, J., Fink, N., Bitzer, J., Hösli, I., Holzgreve, W., 2007. Depression and anxiety during pregnancy: A risk factor for obstetric, fetal and neonatal outcome? A critical review of the literature. J. Matern. Neonatal Med. 20, 189-209.

Amis, D., 2016. The role of the childbirth educator in supporting vaginal birth and reducing primary cesareans: highlights from the California maternal quality care collaborative toolkit. J. Perinat. Educ. 25, 208-214.

Anim-Somuah, M., Smyth, R.M., Jones, L., 2011. Epidural versus non-epidural or no analgesia in labour. Cochrane Database Syst. Rev.
Bandura, A., 1986. Social Foundations of Thought and Action: A Cognitive Social Theory. Prentice Hall, Englewood Cliffs, New York.

Bandura, A., 1982. Self-efficacy mechanism in human agency. Am. Psychol. 37, $122-147$.

Bandura, A., 1977. Self-efficacy: toward a unifying theory of behavioral change. Psychol. Rev. 84, 191-215.

Bar-On, S., Benyamini, Y., Ebrahimoff, M., Many, A., 2014. Mother knows best? Comparing primiparous parturients' expectations and predictions with actual birth outcomes. J. Perinat. Med 42, 435-439.

Beebe, K.R., Lee, K.A., Carrieri-Kohlman, V., Humphreys, J., 2007. The effects of childbirth self-efficacy and anxiety during pregnancy on prehospitalization labor. J. Obstet. Gynecol. Neonatal Nurs. 36, 410-418

Bergström, M., Kieler, H., Waldenström, U., 2009. Effects of natural childbirth preparation versus standard antenatal education on epidural rates, experience of childbirth and parental stress in mothers and fathers: a randomised controlled multicentre trial. BJOG An Int. J. Obstet. Gynaecol. 116, 1167-1176.

Bershadsky, S., Trumpfheller, L., Kimble, H.B., Pipaloff, D., Yim, I.S., 2014. The effect of prenatal Hatha yoga on affect, cortisol and depressive symptoms. Complement. Ther. Clin. Pract. 20, 106-113.

Birks, M., Mills, J., 2011. Grounded Theory: A Practical Guide. SAGE, London.

Brand, G., Morrison, P., Down, B., Westbrook, B., 2014. Scaffolding young Australian women's journey to motherhood: a narrative understanding. Health Soc. Care Comm. https://doi.org/10.1111/hsc.12106.

Bryant, A., 2002. Re-grounding grounded theory. JITTA J. Inf. Technol. Theory Appl $4,25-41$

Campbell, V., 2018. 'Just breathe': How yoga for pregnancy can enable women to use pain-management strategies effectively in labour. Int. J. Birth Parent Educ. $5,20-25$

Campbell, V.R., Nolan, M., 2016. A qualitative study exploring how the aims, language and actions of yoga for pregnancy teachers may impact upon women's self-efficacy for labour and birth. Women and Birth 29.

Commission, Care Quality, 2015. Maternity services survey 2015 https://www.cqc org.uk/content/maternity-services-survey-2015.

Carlsson, I.-M., Ziegert, K., Nissen, E., 2015. The relationship between childbirth selfefficacy and aspects of well-being, birth interventions and birth outcomes. Midwifery $31,1000-1007$

Carlsson, I.-M., Ziegert, K., Nissen, E., 2014. Psychometric properties of the Swedish childbirth self-efficacy inventory (Swe-CBSEI). BMC Pregnancy Childbirth $14,1$.

Charmaz, K., 2003. Grounded theory, Strategies of Qualitative Inquiry. SAGE Publications, Inc, Thousand Oaks, CA.

Creswell, J.W., 2012. Qualitative Inquiry and Research Design: Choosing Among Five Approaches, 3rd SAGE Publications, London.

Cunqueiro, M.J., Comeche, M.I., Docampo, D., 2009. Childbirth self-efficacy inventory: psychometric testing of the Spanish version. J. Adv. Nurs. 65, 2710-2718.

Curtis, K., Weinrib, A., Katz, J., 2012. Systematic review of yoga for pregnant women: current status and future directions. Evidence-Based Complement. Altern. Med 2012, 1-14.

Davis, K., Goodman, S.H., Leiferman, J., Taylor, M., Dimidjian, S., 2015. A randomized controlled trial of yoga for pregnant women with symptoms of depression and anxiety. Complement. Ther. Clin. Pract. 21, 166-172.

Deshpande, C.S., Rakshani, A., Nagarathna, R., Ganpat, T.S., Kurpad, A., Maskar, R., Sudheer, D.C., Nagendra, H.R., Abbas, R., Raghuram, N., 2013. Yoga for high risk pregnancy: a randomized controlled trial. Ann. Med. Health Sci. Res. 3, 341-344.

Doran, F., Hornibrook, J., 2013. Women's experiences of participation in a pregnancy and postnatal group incorporating yoga and facilitated group discussion: A qualitative evaluation. Women and Birth 26, 82-86.

Dwyer, S.C., Buckle, J.L., 2009. The space between: on being an insider-outsider in qualitative research. Int. J. Qual. Methods 8, 54-63.

Eri, T.S., Bondas, T., Gross, M.M., Janssen, P., Green, J.M., 2015. A balancing act in an unknown territory: A metasynthesis of first-time mothers' experiences in early labour. Midwifery 31, e58-e67.

Escott, D., Slade, P., Spiby, H., 2009. Preparation for pain management during childbirth: The psychological aspects of coping strategy development in antenatal education. Clin. Psychol. Rev. 29, 617-622.

Escott, D., Slade, P., Spiby, H., Fraser, R.B., 2005. Preliminary evaluation of a coping strategy enhancement method of preparation for labour. Midwifery 21, 278-291.

Escott, D., Spiby, H., Slade, P., Fraser, R.B., 2004. The range of coping strategies women use to manage pain and anxiety prior to and during first experience of labour. Midwifery 20, 144-156.

Fenwick, J., Hauck, Y., Downie, J., Butt, J., 2005. The childbirth expectations of a self-selected cohort of Western Australian women. Midwifery 21, 23-35.

Field, T., 2016. Yoga research review. Complement. Ther. Clin. Pract 24, 145-161.

Fisher, C., Hauck, Y., Fenwick, J., 2006. How social context impacts on women's fears of childbirth: A Western Australian example. Soc. Sci. Med. 63, 64-75.

Gagnon, A.J., Sandall, J., 2007. Individual or group antenatal education for childbirth or parenthood, or both. Cochrane Database Syst. Rev.

Glaser, B.G., Strauss, A.L., 1967. The discovery of grounded theory: Strategies for qualitative research. Aldine Trans. New Brunswick.

Hall, H.G., McKenna, L.G., Griffiths, D.L., 2012. Applying grounded theory to midwifery research problems. Int. J. Childbirth 2, 136-141.

Holton, J.A., 2007. The coding process and its challenges. In: Bryant, A., Charmaz, K. (Eds.), The SAGE Handbook of Grounded Theory. SAGE Publications Ltd, London, p. 265. 
Ip, W.Y., Chan, D., Chien, W., 2005. Chinese version of the childbirth self-efficacy inventory. J. Adv. Nurs. 51, 625-633.

Ip, W.Y., Tang, C.S.K., Goggins, W.B., 2009. An educational intervention to improve women's ability to cope with childbirth. J. Clin. Nurs. 18, 2125-2135.

Jackson, T., Pope, L., Nagasaka, T., Fritch, A., Iezzi, T., Chen, H., 2005. The impact of threatening information about pain on coping and pain tolerance. Br. J. Health Psychol. 10, 441-451.

Jiang, Q., Wu, Z., Zhou, L., Dunlop, J., Chen, P., 2015. Effects of yoga intervention during pregnancy: a review for current status. Am. J. Perinatol. 32, 503-514.

Jones, L., Othman, M., Dowswell, T., Alfirevic, Z., Gates, S., Newburn, M., Jordan, S., Lavender, T., Neilson, J.P., 2012. Pain management for women in labour: an overview of systematic reviews. Cochrane Database Syst. Rev.

Karlsdottir, S.I., Halldorsdottir, S., Lundgren, I., 2014. The third paradigm in labour pain preparation and management: the childbearing woman's paradigm. Scand. J. Caring Sci. 28, 315-327.

Kassebaum, N.J., Bertozzi-Villa, A., Coggeshall, M.S., Al, E., 2014. Global, regional, and national levels and causes of maternal mortality during 1990-2013: a systematic analysis for the Global Burden of Disease Study 2013. Lancet 384, 980-1004.

Kay, L., Downe, S., Thomson, G., Finlayson, K., 2017. “Engaging with birth stories in pregnancy: a hermeneutic phenomenological study of women's experiences across two generations. BMC Pregn. Childbirth 17, 283.

King, N., Horrocks, C., 2010. Interviews in qualitative research. SAGE Publications, London.

Koelewijn, J.M., Sluijs, A.M., Vrijkotte, T.G.M., 2017. Possible relationship between general and pregnancy-related anxiety during the first half of pregnancy and the birth process: a prospective cohort study. BMJ Open 7, e013413. https: //doi.org/10.1136/bmjopen-2016-013413.

Larsen, R., Plog, M., 2012. The effectiveness of childbirth classes for increasing selfefficacy in women and support persons. Int. J. Childbirth 2, 107-114.

Levett, K.M., Smith, C.A., Bensoussan, A., Dahlen, H.G., 2016. The complementary therapies for labour and birth study making sense of labour and birth - experiences of women, partners and midwives of a complementary medicine antenatal education course. Midwifery 40, 124-131.

Lincoln, Y.S., Denzin, N.K., 2003. Turning points in qualitative research: Tying knots in a handkerchief. Altamira Press, Walnut Creek, CA

Lowe, N.K., 2000. Self-efficacy for labor and childbirth fears in nulliparous pregnant women. J. Psychosom. Obstet. Gynecol. 21, 219-224.

Lowe, N.K., 1993. Maternal confidence for labor: Development of the childbirth self-efficacy inventory. Res. Nurs. Health 16, 141-149.

Lowe, N.K., 1991. Maternal confidence in coping with labor a self-efficacy concept. J. Obstet. Gynecol. Neonatal Nurs. 20, 457-463.

Lowe, N.K., 1989. Explaining the pain of active labor: the importance of maternal confidence. Res. Nurs. Health 12, 237-245

Maharana, S., Nagarathna, R., Padmalatha, V., Nagendra, H., Hankey, A., 2013. The effect of integrated yoga on labor outcome: a randomized controlled study. Int. J. Childbirth 3, 165-177.

Maimburg, R.D., Væth, M., Dürr, J., Hvidman, L., Olsen, J., 2010. Randomised trial of structured antenatal training sessions to improve the birth process. BJOG An Int. J. Obstet. Gynaecol. 117, 921-928.

Marc, I., Toureche, N., Ernst, E., Hodnett, E.D., Blanchet, C., Dodin, S., Njoya, M.M., 2011. Mind-body interventions during pregnancy for preventing or treating women's anxiety. Cochrane Database Syst. Rev.

McMillan, A.S., Barlow, J., Redshaw, M., 2009. Birth and beyond: A review of the evidence about antenatal education. Department of Health (DH).

Mercer, J., 2007. The challenges of insider research in educational institutions: wielding a double-edged sword and resolving delicate dilemmas. Oxford Rev. Educ. 33, 1-17.

Mills, J., Bonner, A., Francis, K., 2006. Adopting a constructivist approach to grounded theory: Implications for research design. Int. J. Nurs. Pract. 12, 8-13.

Mitchell, J., Field, T., Diego, M., Bendell, D., Newton, B., Newton, R., Pelaez, M., 2012. Yoga reduces prenatal depression symptoms. Psychology 03, 782-786.

Mitchell, M., 2013. Women's use of complementary and alternative medicine in pregnancy: a journey to normal birth. Br. J. Midwifery 21, 100-106.

Muzik, M., Hamilton, S.E., Lisa Rosenblum, K., Waxler, E., Hadi, Z., 2012. Mindfulness yoga during pregnancy for psychiatrically at-risk women: Preliminary results from a pilot feasibility study. Complement. Ther. Clin. Pract. 18, 235-240.

NCT and The University of Worcester, 2016. The Yoga Pathway Logbook Foundation Degree Birth and Beyond. Internal logbook Unpublished.

Newnham, J., A, W., Hurley, J., Aplin, J.D., Westwood, M., 2014. Effects of antenatal yoga on maternal anxiety and depression: A randomised controlled trial. Depress. Anxiety 31, 631-640.
O’Mahony, F., Hofmeyr, G.J., Menon, V., 2010. Choice of instruments for assisted vaginal delivery. Cochrane Database Syst. Rev.

Rakhshani, A., Nagarathna, R., Sharma, A., Singh, A., Nagendra, H.R. 2015, A holistic antenatal model based on yoga, ayurveda, and vedic guidelines. Health Care Women Int 36, 256-275

Riley, K., Drake, E., 2013. The effects of prenatal yoga on birth outcomes: a systematic review of the literature. J. Prenat. Perinat. Psychol. Heal. 28, 3-19.

Salomonsson, B., Berterö, C., Alehagen, S., 2013a. Self-efficacy in pregnant women with severe fear of childbirth. J. Obstet. Gynecol. Neonatal Nurs. 42, 191-202.

Salomonsson, B., Gullberg, M.T., Alehagen, S., Wijma, K., 2013b. Self-efficacy beliefs and fear of childbirth in nulliparous women. J. Psychosom. Obstet. Gynecol. 34, 116-121.

Satyapriya, M., Nagaathna, R., V, P., R, N.H., 2013. Effect of integrated yoga on anxiety, depression \& well being in normal pregnancy. Complement. Ther. Clin. Pract. 19, 230-236

Savage, J.S., 2006. The lived experience of knowing in childbirth. J. Perinat. Educ. 15, $10-24$

Schwartz, L., Toohill, J., Creedy, D.K., Baird, K., Gamble, J., Fenwick, J., 2015. Factors associated with childbirth self-efficacy in Australian childbearing women. BMC Pregn. Childbirth 15, 29.

Sheffield, K.M., Woods-Giscombé, C.L., 2015. Efficacy, feasibility, and acceptability of perinatal yoga on women's mental health and well-being: a systematic literature review. J. Holist. Nurs 64-79.

Shope, J.H., 2006. "You can't cross a river without getting wet": a feminist standpoint on the dilemmas of cross-cultural research. Qual. Inq. 12, 163-184.

Sieber, S., Germann, N., Barbir, A., Ehlert, U., 2006. Emotional well-being and predictors of birth-anxiety, self-efficacy, and psychosocial adaptation in healthy pregnant women. Acta Obstet. Gynecol. Scand. 85, 1200-1207.

Slade, P., MacPherson, S.A., Hume, A., Maresh, M., 1993. Expectations, experiences and satisfaction with labour. Br. J. Clin. Psychol. 32, 469-483.

Smith, H., Peterson, N., Lagrew, D., Main, E., 2016. Toolkit to support vaginal birth and reduce primary cesareans: a quality improvement toolkit. Stanford, CA.

Spiby, H., Slade, P., Escott, D., Henderson, B., Fraser, R.B., 2003. Selected coping strategies in labor: an investigation of women's experiences. Birth 30, 189-194.

Sun, Y.C., Hung, Y.C., Chang, Y., Kuo, S.C., 2010. Effects of a prenatal yoga programme on the discomforts of pregnancy and maternal childbirth self-efficacy in Taiwan. Midwifery 26, e31-e36.

Taheri, Z. Mazaheri, M.A., Khorsandi, M., Hassanzadeh, A., Amiri, M., 2014. Effect of educational intervention on self-efficacy for choosing delivery method among pregnant women in 2013. Int. J. Prev. Med. 5, 1247-1254.

Taylor, C., 2005. Interviewing. In: Holloway, I. (Ed.), Qualitative Research in Health Care. Open University Press, Berkshire, England, pp. 38-55.

Thomas, G., James, D., 2006. Reinventing grounded theory: some questions about theory, ground and discovery. Br. Educ. Res. J. 32, 767-795.

Thomson, G., Stoll, K., Downe, S., Hall, W.A., 2017. Negative impressions of childbirth in a North-West England student population. J. Psychosom. Obstet. Gynecol. 38, 37-44.

Tilden, E.L., Caughey, A.B., Lee, C.S., Emeis, C., 2016. The effect of childbirth self-efficacy on perinatal outcomes. J. Obstet. Gynecol. Neonatal Nurs. 45, 465-480.

Welsh, E., 2002. Dealing with data: Using NVivo in the qualitative data analysis process. Forum: Qualitative Social Research 3, art. 26.

Wharton, K.R., Ecker, J.L., Wax, J.R., 2017. Approaches to limit intervention during labor and birth committee on obstetric practice.

Whitburn, L.Y., Jones, L.E., Davey, M.-A., Small, R., 2014. Women's experiences of labour pain and the role of the mind: an exploratory study. Midwifery 30, 1029-1035. 